\title{
Teamwork: A Valuable Moral Resource for Enacting Moral Purpose
}

\author{
Matome L Ramalepe \\ Mathematics teacher and Head of Department (HoD), Limpopo Department of Education, and \\ Teaching Assistant, University of South Africa (UNISA) \\ tetelo4life@ymail.com
}

\begin{abstract}
It is an irrefutable reality that the South African schools are performing below expectation, compared with more poorly resourced systems in the Southern and Eastern subcontinent. The larger study from which this article is drawn found that moral purpose is a compelling moral imperative that can move schools from ineffectiveness and accelerate improvement of the quality of learning outcomes such as grade 12 examination results. However, the study found that the enactment of moral purpose could be adversely hindered by the presence of top-down management approach which usually grants the principal unassailable power and control over all school activities. The findings of this study highlight that moral purpose flourishes in schools which uphold team management; these are schools where teamwork thrives within the SMTs. A compelling view held by the participants in this study is that the SMTs need to model teamwork in their schools to provide an environment in which learning can be articulated, tested and refined. Therefore, the objectives of this article is: (1) to analyse and discuss the educational leadership approach taken to accelerate the cultivation of moral purpose and (2) to examine the extent to which this leadership approach had influenced learner achievement.
\end{abstract}

Keywords: Teamwork, moral purpose, team management

\section{INTRODUCTION}

The notion of using team management in schools was born because of the report submitted by The Task Team on Education Management Development (DoE, 1996). The report recommended the replacement of a top-down management model which granted the principal unassailable power and control over all activities within a particular school with the notion that stressed that school management should be stretched over a range of people. This model is premised on the elements of "participative 'democratic' management, collegiality, collaboration, schools as open and learning organisations, and, importantly, site-based management" (Van der Mescht, 2008:14). Informed by the Task Team's report, the notion of using School Management Teams (SMTs) was born. The SMT is the group of leaders comprising of all educators with management roles, the principal, deputy principal(s) and heads of department.

Substantially, when people label a group of leaders a 'team' they do so to articulate the notion of teamwork sparked by a common goal. This means that teams must "integrate, synthesise, and share information, and they need to coordinate and cooperate as task demands shift throughout a performance episode to accomplish their mission" (Salas, Cooke \& Rosen, 2008:541). It can be argued from this that the SMT is called a "team" because its members are expected to make sound decisions together and implement those decisions to achieve the common goal or mission. It was against this background that the study was conducted to examine how the school management teams pursue and cultivate moral purpose, the central goal of this moral purpose being to gradually improve learner achievement.

When team members engage in interdependent interactions as they perform their tasks, when they share responsibilities and accountability for the outcomes of the tasks in pursuit of their moral purpose, they enter into teamwork processes. According to Mendwell (2009), teamwork is a gathering of workgroup of individual people by prescribing purposes or goals and encouraging effective communication and cooperation within the workgroup. In essence, teamwork encourages the transference of certain powers and responsibilities about the task to be done to the team in order to 
accelerate team effectiveness. The word "effective" suggests that the quality of the task accomplishment is the best available and achievable within the time available, and that the team makes full and economic use of the resources available (Everard \& Morris, 1996:156, 2006:156). This word suggests that team goal or outcomes of the task performed are achieved within a prescribed timeframe with resources well utilised. Thus, Hackman (1987) defines team effectiveness as an evaluation of the outcomes of team performance processes relative to some set of criteria. These criteria can include evaluation of task completion, team development and stakeholder satisfaction (Helriegell et al., 2008).

With regard to task completion, the criteria can involve measuring aspects such as accuracy, speed, creativity and cost. This means that effective teams should be able to complete team tasks with accuracy, speed, creativity while making good use of the available resources. Team development also includes team cohesiveness, team flexibility and team preparedness for new tasks. This means that any team develops into an effective team when its members are committed to that team and also have the desire to remain in the team. Therefore, "effective teams are identified by the following features, namely, a willingness by members to share, even to sacrifice, having an agreed purpose or mission, and the team achieving more than the sum of its constituent parts" (Darren, 2010:71). Darren's (2007) claim is reinforced by the Department of Education's Education Law and Policy Handbook when it states that "teams that produce good results usually have a common purpose, clearly defined roles for each team member, a leader, team members that support one another, a free flow of information, set ways for resolving conflict, and members who can see benefits in working together" (DoE, 2000:26).

However, teamwork effectiveness could be challenged by factors inherent within the school context. Perhaps this is as Stott and Walker (1999:55) warn "Teamwork effectiveness could be seriously impaired in schools that foster secrecy and suspicion. In such conditions, people play safe and pursue low-risk strategies. An absence of interdependence and the pressure of high levels of animosity between team [members] may affect overall organisational performance". Stott and Walker's warning is genuine because in an environment where distrust and disloyalty prevail, team members prefer to work in isolation. In this way the expertise and abilities of members become dislocated and isolated, resulting in team's failure to achieve expected outcomes.

\subsection{The Merits of Teams and Teamwork in Schools}

The importance of teams and teamwork are fully documented. Scott and Walker (1999:51) identified collaboration, empowerment, co-operation and consultation as the benefits of teamwork. They further cite arguments that teamwork provides teachers with a "significant role in school decision making", and "control over their work environment". This claim finds support in Van der Mescht and Tyala (2008:230) who assert that problems can be solved more creatively if the SMT functions as a team rather than as individuals. The availability of teams ensures that a wider range of problem solving than a single individual could cope with is covered. This means that working as a team promotes problem ownership in which team members view problems as team problems and jointly contribute their expertise and capabilities to resolve those problems. Therefore, teams are desirable because during the process of problem solving creative talents are harnessed and maximised within the school and learning is promoted. Teams are, therefore, learning units because they encourage the transfer of knowledge as well as skills. School teams have a potential to nurture and optimise the talents and skills of those involved in them. I argue in this way because I believe that, when team members interact, they sharpen each other's skills and talents. It is a notion of "iron sharpening iron", when each member is given enough opportunity to exercise his or her skills and talents to benefit and equip others.

Teamwork also provides opportunity for members' skills and capabilities to be evaluated throughout and in so doing adjustments could be made in order to have them functioning to their maximum (Tyala, 2004). The optimum functioning of every team member makes the school achieve its core duty of educating learners.

\subsection{Threats to Teams and Teamwork in Schools}

While the benefits of team management and teamwork are widely articulated, there are challenges to teamwork or to keeping the team together. Tondeur (2008) identifies trust, communication lines, keeping morale, good leadership and responsible membership at the highest level as challenges affecting teamwork. Van der Mescht and Tyala (2008) include "various levels of competence among 
team members" as a threat to teamwork as distributing responsibilities to members who may not be competent might threaten the effective functioning of the school. In this regard, relying on other team members may mean that the school might not meet due dates and "the major thing is to meet due dates by the department" (Tonduer, 2008:302). On the other hand, laziness of some of the educators who want to do the basic minimum is also a challenge (Van der Mescht \& Tyala, 2008). A team member (principal, head of department or deputy principal) who is lazy may lead to some members of the team being overloaded, and this threatens the team-building process in the school.

Another challenge that hampers teamwork in school relates to delegation and job satisfaction. Sometimes principals find it difficult to delegate responsibilities to other team members because they believe the job may not be done the way they would like it, and they then may not get that personal satisfaction. The need for personal satisfaction with job well done could drive principals to tackle projects individually rather allowing the participation of other team members (Tonduer, 2008). When school principals start to express reservations about delegating responsibilities, perhaps because they doubt the abilities of their colleagues, they create a tension between "holding on and letting go" (MacBeath, 2005:354). To overcome this threat, school principals should focus on professional and human resource development. Once team members are capacitated, the principal should decide to build a school culture premised on trust which will facilitate the distribution of leadership. Trust is acknowledged as being the root of success or failure in relationships, and communicates credibility in leadership.

However, MacBeath (2005) warns that building a culture of trust in the face of accountability pressures implies a risk. The risk is that trust may be placed in people who do not honour that trust and, in so doing, only the principal is left accountable to the Department and other stakeholders for the task poorly done. This is because within the legal framework of South Africa's education system, school principals are ultimately accountable because they possess statutory delegated authority (Mbatha, Grobler \& Loock, 2006). But the alternative of working in a culture of mistrust is equally unappealing because "without mutual trust, relationships and respect are compromised and mistrust exerts a corrosive influence" (MacBeath, 2005:353). Thus, the development of mutual trust is a nonnegotiable in the practice of team management and the challenge for SMT members, especially the school principal, is to find and utilise areas of expertise in colleagues because trust is earned through expertise (Grant, Gardner, Kajee, Moodley \& Somaroo, 2010).

The challenge facing principals is how to balance the important issue of developing trust with the equally important issue of accountability. In response to this challenge, Van der Mescht and Tyala (2008:227) suggest that the principal's role becomes "a balancing role" where the principal is challenged to determine, in line with legislation, what practices can be distributed and how the distribution will happen. When the "balancing role" of the school principal is performed effectively, team members bond and respect each other while satisfying expectations of the Department, for example, meeting all due dates, while relieving accountability pressure on the school principal. In direct contrast, school principals who fail in their "balancing role" usually collapse under the pressure of accountability, and under these circumstances they end up not consulting other team members. Ultimately, as a result of this pressure, these principals end up hiding under the accountability niche of "I am the accounting officer" to justify their lack of consultation. Sometimes resorting to this accountability niche is not voluntary, but is indicative that the "school manager is torn between efficiency, that is, making quick decisions without consulting and real teamwork, i.e. taking time to consult and really listen to others' views" (Van der Mescht \& Tyala, 2008).

Furthermore, lack of consultation is interpreted by most school principals as merely a matter of not having time to consult or the decision couldn't wait a day or two. The challenge is seeing teamwork as time consuming as it takes time for team members to reach common opinion about something and issues that need urgent attention sometimes do not get it (Tondeur, 2008). While it is true that some decisions need to be made quickly and therefore can and should be taken by the principal, it is equally true that most really important decisions can be delayed. In this regard, Van der Mescht and Tyala (2008) argue that perhaps failing to consult and really use teams stem from lack of real commitment to the process of decision-making through which personal and professional growth is enhanced. They further argue that leaders who insist on consultation and constantly look for ways of achieving group decisions are simply expressing their respect for their colleagues, and reinforcing their commitment to relationships and personal growth. It is therefore argued here that teams' survival depends on the level of consultation expressed by the school principal and other members of the SMTs. 


\section{MATerials AND MethodS}

The larger study from which this paper is drawn preferred qualitative approach as a most suitable design to interpret and understand the experiences and perceptions of school managers. The findings presented in this article are part of a larger study in which fifteen participants were asked eleven openended questions about various aspects of moral purpose. These eleven sub-questions fell under four primary questions. For the purposes of this article, only one question was considered, which led to two primary objectives: (1) to discover how selected school managers identify as an educational approach taken to cultivate moral purpose in their schools and (2) to examine the effects of this approach on school leadership and learner achievement. Purposive sampling technique was employed to select participants [principals, deputy principals and heads of department] from the population who were representative of the larger group of Limpopo school managers or they were informative about the topic of interest (McMillan \& Schumacher, 1993, 2006). The final group of participants included three school principals, two deputy principals and ten heads of department. Although the study employed three separate yet complementary data collection instruments, individual semi-structured interviews were the major focus.

Therefore, this article discusses the findings obtained through semi-structured interviews conducted with members of the school management teams. All the interviews were audio taped. In addition, during the interviews, I wrote notes about the answers of the participants to later develop tentative ideas regarding categories and relationships (Maxwell, 2008). The interviews lasted from 30 to 60 minutes. Interview tapes were transcribed verbatim. Data was examined and organised according to the four research questions. During this research all reasonable steps to maintain the confidentiality and anonymity of the participants were taken. These steps revolved around dual responsibility described by McMillan and Schumacher (1993:399): firstly, "the protection of the participant's confidentiality from other actors in the setting whose private information might enable them to identify them and, secondly, the protection of informants from the general reading public". In line with this, I did not reveal information about the attitudes, motivations or behaviour that a participant would rather not have revealed (Thompson, 2008). The real names of schools and participants were changed to ensure anonymity and confidentiality (e.g. Apple High School: Principal).

\section{RESUlTS AND DISCUSSION}

This section is a narrative description of the answers the participants provided to the interview questions: "What would you identify as an educational approach taken to cultivate moral purpose in your school?" and "To what extent has this educational approach influenced leadership and learner achievement in the school over the past three years? Responses to these two questions provided clarity on why other schools succeed in cultivating moral purpose, while others fail despite of the similar contextual factors.

\subsection{Teamwork: A Valuable Resource for Achieving the Goal of Moral Purpose}

The picture elicited by this research is that the central goal of moral purpose is to raise the achievement level for all learners in schools. But the participants were of the view that this goal can only be achieved when teamwork prevails within the SMTs and other teams. Teamwork was widely acknowledged by the research participants not only as an alternative notion to 'sole' principalship but also as a key driver for effective cultivation of moral purpose in schools. A useful starting point for the examination of these aspects was the acknowledgement that the notion of working together as a team is fundamental to the efficacy of the SMTs in cultivating moral purpose of academic achievement for all learners:

Achievement of learners starts with teamwork. Everything starts with teamwork ... whenever there is something, the way we exchange, the way in which we assist each other, we work as a team. And then even the teachers out there when they see us they see this team spirit. It is difficult nowadays to get people to operate as a team. But if you come to Apple High School, there are different because these people work as a team, they understand each other. We are all focused; we know what we want, and where we are heading to. The reason why the school is so successful in terms of grade twelve results is because of teamwork, of sharing, of ideas and consultation, not undermining each other (Apple High School Principal).

Another participant, the school principal also espoused on team notion as a key approach for enhancing moral purpose of academic achievement in his school: "Under normal circumstances the 
school is doing well because we work as a team. And I believe it got team leadership ... that is what put our learners on the map." The perceptions of the two principals above are that by espousing the notion of teamwork not only as democratically viable but also as morally acceptable has helped their schools to improve learner achievement. Therefore, the realization of the goal of moral purpose depends largely on the capacity of SMTs to foster teamwork and this improves cooperation among team members. Commenting on this cooperation, another participant who is the head of department stated that "... if teacher A is not present, then, I have to check who can help those learners ... We had a challenge of teacher $X$ who was on sick leave, to indicate that teamwork is there, I happened to take over his subject." The participants held the strong view that teamwork facilitates the cultivation of moral purpose because it provides an opportunity for the SMTs to share ideas, responsibilities and accountability for the outcomes of the leadership functions in the school. The notion of 'sharing' allows the SMTs to have a wider range of ideas to solve problems than a single manager. Accordingly, Darren (2010:71) identified "a willingness by members to share, even to sacrifice" as a key feature marking the effectiveness of the SMTs.

However, sharing is only possible in teams that are "having communication, having cooperation, and knowledge and ability to work together in making work plans to accomplish the goal" (Mendwell, 2009:320). That is, it would be impossible for members of the SMTs to be willing to share in an environment in which principals have restricted channels of communication and members have no skills in collaboration. It is therefore important to equip SMT members with good communication skills and develop their understanding of team dynamics such as respect and patience. Another key dimension of teamwork that emerged in my research is that teamwork consists of a collection of individuals who are not only interdependent in their tasks but "who [also] see themselves and who are seen by others as an intact social entity ... who manage their relationship across organizational boundaries" (Cohen \& Bailey, 2007:106). In this view, the participant in one of the highest performing schools indicated that "Our SMT is seen by teachers and learners as a united entity that shares responsibility as they pursue the moral purpose of the school" He further claimed that "Teachers and learners respect us because they see us as a team that sings the same tune every time we approach them with the decisions taken in our SMT meetings. The "united entity" highlighted as an ideal by school managers means oneness. This is a unit that does everything in the spirit of succeeding. To be seen by others as a unit requires the ability of the SMT members to effectively manage their interpersonal relationships. Staff is unlikely to respect an SMT that is characterized by tensions and struggles within the team.

Of interest in this study is that the two principals interviewed highlighted that teamwork encourages other members to offer them support. A participant who is a school principal indicated that "I want to show them that without them I am nothing. And that they must understand that the principal wants to work with us, and then let us support him." According to Tyala (2007:84), this support is in terms of "positive criticism, advice, correction, encouragement and different ideas". Participants in this study regarded support as an important ingredient of teamwork and concede that it is impossible to achieve the goal of moral purpose without it. As Scott and Walker (1999:50) argue that "Without the right form of support, teamwork can be a little more than a token of democracy, and if schools are to optimise their use of teams, they must face up to some of the inconsistence evidence in their structures, systems and processes". My research has proved that whenever there are structures and systems of support in place in a school, the notion of teamwork becomes more effective, and the ultimate end results are evidence of learner achievement. The research participants were also of the view that SMTs need to be constantly supported by all the stakeholders involved so that they can execute their functions confidently. This support should come from the provincial, district and circuit levels as well as from the community.

\subsection{Participative Decision-Making: Key Driver of Teamwork in Effective Schools}

For teamwork to thrive, negotiating needs to be coupled with an emphasis on participative decisionmaking. The emphasis on participative decision-making is based on the assumptions that participation will increase school effectiveness and that in the context of site-based management, leadership is potentially available to any legitimate stakeholder (Leithwood, Jantzi \& Steinbach, 1999). It emerged strongly that the school principals in effective schools viewed participative decision-making in schools as a notion that emphasises the involvement of other leaders, teachers, learners and parents. On the involvement of leaders and teachers, a participant who is a school principal stated that "Each and every time whenever there is a decision to make, be it about achievement of learners or school 
programme, I call my colleagues and teachers and say guys here is the issue, let us sit around the table and discuss." The development of team management means that school management is not located only in the position of the school principal and this leads to facilitation that ensures that "decision-making processes, the crafting of a vision and mission of the school, the setting of the school ethos rest with the schools' stakeholders" (DoE, 2002:2). Owens (2001:288) argues that "In participative decision-making, all members have the right to be heard, to have their views considered, to express feelings, to offer knowledge and information". This was very prominent in the responses of the participants and my observations complemented this. All the meetings I observed were conducted in a very relaxed manner that allowed each member to be free to contribute his or her ideas. Undoubtedly, if meetings are conducted in that fashion all team members will own the decisions taken at those meetings because ".. it is only if people are involved in the process of decision-making that they will own the decision taken" (Udjombala, 2002:49). The inclusion of various stakeholders in decision-making has not only endorsed the democratic nature of the school, but can also enhance learner achievement. This is so because people who have helped make decisions about standards or achievement goals for learners are likely to modify their behaviours in order to attain the goals.

On the inclusion of learners in decision-making, one school principal claimed "... we also work with the learner representative council and matric board ..." It was clear that most schools elicit support from various learner structures such as the Matric Board and Representative Council of Learners to promote a disciplined environment.

Furthermore, participants commented on the imperativeness of participative decision making that involves parents. One Head of Department stated that "But now we are trying to involve parents and even the learners themselves in whatever decision we take they are involved." The overall picture that emerged indicates that the role played by parents is generally acknowledged and welcomed by SMTs. The Banana High School Principal highlighted the importance of parent involvement and said "Normally what we do every year, we invite parents and we talk to them about how we are going to run the school the whole year, so that the parents are able to support us." Specifically, since the goal of learner achievement concern the entire staff, parents and learners, it is important to involve them because "The basic aspects of democracy are participation and involvement of people in issues affecting their lives" (Tyala, 2004). A participant in this study stated "This involvement of stakeholders including staff should be in all decisions that involve them, “... from big change programmes, to the day-to-day decisions on how services are delivered" (Munro, 2003:278). This is an ideal democratic situation, but practical situations in most of our schools suggest otherwise. My observations can affirm that in most instances it is easy for the school principal to decide solely on what they personally regard as trivial or insignificant matters of day-to-day school operations.

For example, the school principal can decide where to set up a meeting between the HoD and the visiting curriculum advisor without consulting the HoD. In this case, the HoD has got no say about something that affects him or her, whether he or she is comfortable with the venue does not matter. This is a sign that in most schools day-to-day decisions are subject to the impulsive and the undemocratic reaction of the principal when considering consultation on what is considered an insignificant matter. However, it needs to be stated that sometimes unilateral decisions can be justified. One of the research principals indicated that he consults with the other members of the SMT and teachers when he sees fit. According to Tyala (2004), it would be ineffective to wait for the SMT meeting to decide whether to call an ambulance for the learner who has sprained his ankle during break time. In this case, the school principal uses his or her own discretion to solve the problem and is at liberty to decide the solution unilaterally. There is a difference between unilateral decisions and authoritarianism. Authoritarianism compromises the freedom of others in the process of obeying rules set by the school leader while unilateral decision making is considerate of the circumstances around the situation about which the decision is to be made. There will always be situations in the process of cultivating moral purpose where the school principal is required to provide unilateral solutions for the sake of the school.

Evidently, the school principals in this research claimed that in their schools participative decisionmaking has succeeded in "bonding staff together and easing the pressures" on them as they pursue the nourishment of their moral purpose (Sergiovanni, 1984:13). They acknowledged that they cannot claim to have all the answers for everything happening in their schools or all the skills to manage the school. They recognised that "The burdens of leadership will be less if leadership functions and roles 
are shared" (Sergiovanni, 1984:13). They further recognised the importance of cooperation with the school governing body (SGB) as a stakeholder that can assist in maintaining a disciplined environment in their school. Bush and Heystek (2003) point to the need for this co-operation between principals and SGBs if governance is to be effective. Therefore, to turn schools into thriving centres of excellence in which moral purpose thrives, teamwork exemplified in participative decision-making needs to permeate the whole system to involve collaboration between the SMTs and different structures in the school such as the RCLs and SGBs.

\subsection{Factors Barring Teamwork in Underperforming Schools}

While teamwork was widely accepted as a notion that accelerates the enhancement of moral purpose in schools, school managers in underperforming schools highlighted a myriad of factors hampering them from actualising teamwork. Observations conducted in these schools had validated this, and this offers a good case to argue that the actual enactment of teamwork in underperforming schools seems to be wishful thinking. Several observations confirm this conclusion. Firstly, it emerged that participants from the underperforming schools emphasise teamwork to mean a process of allocating duties to different members of the SMTs, and they perceive it as occurring within such a hierarchical arrangement. The ideal of sharing espoused by these SMTs can be undermined by the presence of hierarchies within leadership teams (Glenn, 2009). While it is true that management responsibilities in schools are usually arranged hierarchically, with the principal, deputy principal and heads of departments occupying managerial positions, Ndebele (2007:2) argues that teamwork is "not only what we do together when we have been put in some position of power to steer an organisation or some institution". It is rather a notion that thrives when the traditional hierarchical arrangements are made imperceptible during day-to-day interactions of the members of the SMTs and teachers to allow collaboration or interdependence of members outside restricted boundaries.

In addition, participants from underperforming schools pointed out that there are individuals' behaviour and attitudes that are counterproductive, challenging the efficacy of the SMTs in their schools. One participant stated "... you always have a black sheep in the kraal." He reports that "We have some who are doing other things that are not in line with our team vision and moral purpose, sabotaging our efforts to improve learner achievement" An example of such attitudes is lack of commitment evident with respect to the decisions made by the team (Cole, 2006). Despite consensus about the submission dates for the learners' marks, a member of the SMT in one of the underperforming schools failed to meet the submission due date and, as a result, the school failed to meet due dates set by the circuit. An acting school principal in one of the lower performing schools highlighted this challenge:

As a school we agreed that we will give parents reports when schools reopen. But when we returned, this HOD failed to submit his marks. I went to him and I wanted to know what might be the problem, but he said there was no problem, he just wanted to finalise his work. But one of the educators opened my eyes when she said; you SMT demand submission from us while you yourselves do not comply. Mr. $X$ did not mark his scripts and that is why he did not submit. I had to enter my colleague's office and then indeed I found the scripts on the table, and when I checked the ones on top were marked but the ones below were not marked. I called my colleague who did not mark the scripts, as part of the SMT, I was alone, and he again did not want to come so that we may talk one to one.

The efficacy of SMTs is actually measured by the ability to meet due dates, among other things. Tonduer (2008) concurs that the major thing is to meet due dates set by the Department. It is possible to argue that most underperforming schools comprise managers and teachers who are lazy and, as a result of their laziness, their schools fail to meet the Department's due dates. Accordingly, Van der Mescht and Tyala (2008) identified laziness by some team members as a factor challenging the efficacy of teams. In addition to this challenge is that the research has found evidence of irregular SMT meetings in underperforming schools. This was evident in the old minutes of the previous meetings held by the SMT and staff presented for the purposes of document analysis. The minutes presented were about two to four months old. The infrequency of meetings held by teams is one of the challenges identified in other studies as having a negative impact on teamwork (Cole, 2006). In contrast, the minutes presented by performing schools were recent (two to one month old). My observations at two performing schools also confirmed the frequency of SMT and staff meetings which generally served the purpose of sharing information which provides opportunities for the SMT members and staff to have control over their environment by collectively deciding on what is important for the school and solving problems. 
While school managers from higher performing schools appear to have the capacity to establish teamwork in ensuring diversity of opinion and complementarities of skills within the SMTs, Fullan (1993:64) warns that "a shared sense of purpose and related concerted action is something to work toward, and is never fully achieved". An in-depth analysis of data proved that not all team members in these SMTs are as willing to share as they are portrayed to be. One principal's remarks that "there will always be a black sheep in the kraal" confirmed that. Therefore, considering several barriers that need to be addressed before teamwork thrive in most schools, it would be premature to conclude that all SMTs in performing schools are effective. It seems that the school principals in this research focused on what they would like to see happening in their schools rather than what is actually happening. This shows that teamwork is a process rather than a phenomenon, which needs patience to fully achieve. It should be a goal all members of the SMTs are striving for, bearing in mind that along the way there will be obstacles that need negotiating, failing which, sharing may remain a myth (Tyala, 2004).

\section{4. 'Teaming' Against all Odds: How Effective Schools Overcome Threats to Teamwork}

Both effective and ineffective schools are confronted by similar challenges which could have negative impact on teamwork. The difference is however in how these challenges are confronted and addressed. It emerged in this study that effective schools are always looking for ways to address threats to teamwork because they regard the resourcefulness of teamwork in their schools as outweighing the pain of dealing with its inhibiting factors. Thus, another school principal noted "It is not easy to keep the SMT together, we have challenges of working as a team, but we do it [teamwork] against all odd." Similarly, a head of department responsible for languages in another effective school asserts that the point of departure in addressing the challenges affecting teamwork should be to understand that "... even if we were born on the same day, sharing the same mom, there will always be different people who bring different perspectives to the team ... you then cannot expect to see eye to eye on all issues." He adds that "... but when there are different opinions causing conflicts within the team, we communicate with each other with respect and resolve our conflicts peacefully". His colleague, the deputy principal adds that "...whatever challenges we come across as a team, we rise collectively above them because we have our relationship built on mutual trust and respect". Following these remarks, it is apparent that leaders are likely to have effective teamwork if team relationships are characterised by mutual trust and respect for the subordinates and regard for their feelings.

\section{Conclusion}

Generally, the findings of this research indicate that moral purpose flourishes in schools which uphold team management; these are schools where teamwork thrives within the SMTs. The participants in this study held a view that the SMTs need to model teamwork in their schools to provide an environment in which learning can be articulated, tested and refined. Essentially, the research found that the critical elements of teamwork which can facilitate improvement in team performance and learner achievement are communication, effective coordination and division of work load amongst members. Teamwork at school prevails when there is a commitment of time and resources to build communication skills within the teams. Open and easy communication within the team is critical for goal accomplishment and completion of regular activities within the team. The findings of this research indicate that communication within a team facilitates the sharing of moral purpose, and thus, can discriminate between effective and ineffective teams.

\section{REFERENCES}

Bush, T. \& Heystek, J. (2003). School governance in the new South Africa. Compare, 33, 127-138.

Cohen, L. \& Bailey, D.E. (2007). What makes teams work? Group effectiveness research from shop floor to executive suite. Journal of Management, 23 (3), 239 - 290.

Cole, P. (2006). The leadership team charter: A strategy for strengthening school leadership. The Australian Educational Leadership, 28 (2), 10-12.

Darren, J.E. (2010). An exploration of the role of senior leadership teams in enhancing the mission integrity of selected Catholic schools in the Mercy tradition. Doctoral thesis, Australian Catholic University.

Department of Education (1996). Changing management to manage change in education. Report of the Task Team on Education Management Development. Pretoria: Government Printers. 
Department of Education (2000). Education Law and Policy Handbook. Cape Town: Juta.

Department of Education (2002). The building of capacity of 1500 schools to enable them to be granted section 21 status in 2003. Pretoria: The Department of Education.

Everard, K.B. \& Morris, G. (1996). Effective school management. London: Paul Chapman.

Everard, K.B. \& Morris, G. (2006). Effective school management $\left(2^{\text {nd }}\right.$ Ed.). London: Paul Chapman.

Fullan, M. (1993). Change forces: Probing the depth of educational reform. London: The Falmer Press.

Glenn, M. (2009). Distributed Leadership: A Case Study in Queensland Secondary Schools. Griffith University, Queensland.

Grant, C., Gardner, K., Kajee, F., Moodley, R. \& Somaroo, S. (2010). Teacher leadership: a survey analysis of KwaZulu-Natal teachers' perceptions. South African Journal of Education, 30, 401419.

Hackman, J.R. (1987). The design of work teams. In Lorsch J. (Ed.). Handbook of Organizational Behavior, 315-342. New York: Prentice Hall.

Hellriegel, D., Jackson, S.E., Slocum, J., Staude, G., Amos, T., Klopper, H.B., Louw, L. \& Oosthuizen, T. (2008). Management ( $3^{\text {rd }}$ South African Edition). Oxford: University Press. South Africa.

Leithwood, K., Jantzi, D. \& Steinback, R. 1999. Changing Leadership for Changing Times. Buckingham: Open University Press.

MacBeath, J. (2005). Leadership as distributed: A matter of practice. School Leadership and Management, 25(4), 349-366.

MacMillan, J.H. \& Schumacher, S. (1993). Research in education - a conceptual introduction $\left(3^{\text {rd }}\right.$ Ed). New York: HarperCollins College Publishers.

MacMillan, J.H. \& Schumacher, S. (2006). Research in education - Evidence-based Inquiry (6 ${ }^{\text {th }}$ Ed.). International Edition. Boston: Pearson Education Inc. Pergamous Press.

Maxwell, J.A. (2008). Qualitative research design: An interactive approach $\left(2^{\text {nd }}\right.$ Ed.). Thousand Oaks: Sage.

Mbatha, L., Grobler, B. \& Loock, C. (2006). Delegation of authority by school principals: an education law perspective. Education as Change, 10, 3-15.

Mendwell, J. (2009). Developing a model of Teacher - Team Building at secondary schools in Thailand $\left(5^{\text {th }} \mathrm{Ed}\right.$.). New York: Longman.

Munro, A. 2002. Working Together - involving staff: Partnership working in NHS. Edinburgh: MCB University Publisher.

Ndebele, N. (2009). Perspectives on leadership challenges in South Africa. Perspectives in Education, $25,1-8$.

Owens, R.G. (2001). Organizational behaviour in education: Instructional leadership and school reform $\left(7^{\text {th }}\right.$ Ed.). Boston, Mass: Allyn and Bacon.

Salas, E., Cooke, N.J. \& Rosen, M.A. (2008). On Teams, Teamwork, and Team Performance: Discoveries and Developments. The Journal of the Human Factors and Ergonomics Society, 50, 540.

Sergiovanni, T.J. (1984). Leadership and Excellence in Schooling. Educational Leadership, 41(3), 413.

Scott, K., \& Walker, A. (1999). Extending teamwork in schools: Support and organizational consistency. Team Performance Management, 5(2), 50-59.

Thompson, M. (2008). Ethics (Teach you series). London: Hodder Headline.

Tonduer, N. (2008). Roles, duties and responsibilities of school management team. Mineduc School Management. Kigali: NCDC.

Tyala, Z. (2004). School management team member's perception of their roles in managing Grahamstown secondary schools. MEd thesis, Rhodes University, Grahamstown.

Udjombala, M. (2002). An investigation of management and leadership experiences of female school principals in the Ondangwa education regions. MEd thesis, Rhodes University, Grahamstown. 
Van der Mescht, H. \& Tyala, Z. (2008). School principals' perceptions of team management: a multiple case-study of secondary schools. South African Journal of Education, 28, 221-239.

Van der Mescht, H. (2008). Educational leadership and management - some thoughts from the field. Journal of Education, 44, 7-24.

\section{AUTHOR's BIOGRAPHY}

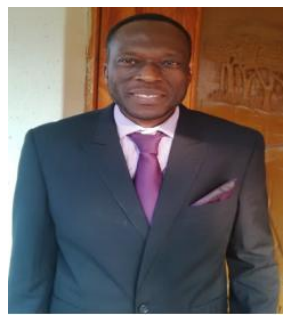

Dr Matome Liphy Ramalepe, holds Doctor of Education in Educational leadership and management from the University of South Africa (UNISA). He currently works as a teaching assistant at UNISA and Mathematics teacher and head of department (HoD) at Mohlatlego Machaba High School, Limpopo Province, SA. 